MEG showed reduced or delayed activation patterns in affected subjects. A previous report of a lateral temporal malformation in ADPEAF is not supported by this study, but the findings point to a functional impairment of language processing. (Ottman, R, Rosenberger L, Bagic A, et al. Altered language processing in autosomal dominant partial epilepsy with auditory features. Neurology Dec 9 2008;71:1973-1980). (Reprints: Dr Ruth Ottman, GH Sergievsky Center, Columbia University, 630 West $168^{\text {th }}$ Street, P\&S Box 16, Ne York, NY 10032. E-mail: ro6@columbia.edu).

COMMENT. Autosomal dominant partial epilepsy with auditory features is an idiopathic focal epilepsy syndrome with auditory symptoms or receptive aphasia. Families with this syndrome commonly have mutations in the LGI1 gene. These authors previously published a review of the genetics of 24 ADPEAF families with mutations in the LGI1 gene (Ped Neur Briefs Sept 2008;22:71).

\title{
PROGNOSIS OF LANDAU-KLEFFNER SYNDROME
}

The long-term follow-up of seven patients with Landau-Kleffner syndrome (LKS) is reported from State University of Campinas, Brazil. All were males between age 8 and 27 years. Parents or patients were interviewed 3 to 16 years after disease onset. All had normal MRIs. All had interictal seizure discharges on the EEG, maximal on the temporal lobes in 5, and exacerbated in sleep. Age of disease onset was 3 to 9 years; 5 patients presented with seizures and 2 with language disorder. Seizures were focal motor in 6 patients; 3 had clonic orofacial movements, 2 had secondarily generalized seizures. Language disorder was insidious in onset in 4 and abrupt in 3. All patients had aphasia and verbal auditory agnosia. Two patients still had seizures at follow-up at 12 and 27 years of age, despite several antiepileptic drugs; seizures had resolved in 4. Language disorder had persisted in 3, it was partially in remission in 3 , and had resolved in 1. Duration of aphasia was 2 to 8 years. One of 4 adult patients is employed, and 3 do not work independently. Three patients are under 13 years of age. Six of 7 patients have severe deficits in communication, and 3 have behavior problems. Only one patient has a normal quality of life. In six with limitations, aphasia/agnosia is the main problem. Shorter duration of aphasia correlates with better outcome. Five patients have normal EEGs, 6-17 years after disease onset; 2 still have abnormal EEGs and refractory seizures. (Duran MHC, Guimaraes CA, Medeiros LL, Guerreiro MM. Landau-Kleffner syndrome: Long-term follow-up. Brain Dev Jan 2009;31:58-63). (Respond: Dr MM Guerreiro. E-mail: mmg@,fcm.unicamp.br). 